\title{
Personalized 1-2-3-gene(s) tickets to cancer-free prostate
}

\author{
Sanda Iacobas ${ }^{1}$ and Dumitru A. Iacobas ${ }^{2, *}$
}

1 Department of Pathology, New York Medical College, Valhalla, NY 10595, USA; sandaiacobas@gmail.com

2 Personalized Genomics Laboratory, Center for Computational Systems Biology, Roy G Perry College of Engineering, Prairie View A\&M University, Prairie View, TX 77446, USA

* Correspondence: daiacobas@pvamu.edu

\begin{abstract}
Many years and \$\$ spent for research did not yet produced a universally effective gene therapy of prostate cancer (PCa). Our studies indicated that not only each human, but even each cancer nodule in the same tumor has unique and dynamic gene expression profile, control and coordination. The tumor heterogeneity of the transcriptome topology is a strong argument in favor of personalized gene therapies, tailored on patients' primary tumor unique characteristics. Here, we propose a bioinformatics procedure by which to identify the Gene Master Regulators (GMR) of cancer cells from transcriptomic data and predict consequences of their experimental manipulation. The procedure, based on our Genomic Fabric Paradigm (GFP), can determine the most important gene in each cancer nodule whose controlled alteration would selectively kill the cancer cells. In this report, the method is applied to our microarray data on two men PCs (each with three distinct cancer nodules) and two standard human PCa cell lines (DU145 and LNCaP). We expect the industry to produce ready-to-use CRISPR constructs for all genes allowing the clinical oncologist to prescribe the adequate personalized CRISPR cocktail for his/her patient. Thus, the GMR approach may provide the most effective, yet affordable solution in fighting cancer.
\end{abstract}

Keywords: AP5M1; BAIAP2L1; CRISPR; ENTPD2; LOC145474; MTOR; PRRG1; VIM; WFDC3

\section{Introduction}

For decades, cancer genomists struggled to identify gene biomarkers whose altered sequence (e.g. [1]) or/and expression (e.g. [2]) is/are indicative for the prostate cancer (PCa) and could serve in active surveillance [3] of PCa development. It was hopped that by skillfully handling such biomarkers the clinician will be able to increase survival rate (e.g. [4]), destroy the cancer cells (e.g. [5]) and reduce their proliferation (e.g. [6]) and spreading (e.g. [7]). Biomarkers' "smart" manipulation was thought also to block the PCa recurrence after various types of treatments (e.g. [8,9].

Problem is that recent evidence indicates that most cancerous prostates harbor genetically distinct, independently developing malign clones [10]. This tumor heterogeneity [11, 12], both at histo-pathological and transcriptomic [13, 14] levels within the prostate of one patient as well as among patients, complicates significantly the treatment options [15-17]. Moreover, together with the biomarker(s) whose altered sequence or expression level is thought indicative for that cancer type, unique combinations of hundreds other genes are mutated or/and regulated in each cancer nodule with respect to the surrounding, cancer-free tissue [18]. The unique combination of affected genes is the direct result of the never repeatable association of favoring factors affecting the entire body (race, age, medical history, habits, diet, stress, climate etc.) and the specific local conditions (microbiome and cellular environment). This explains the observed wide diversity of PCa forms and the large spectrum of treatment outcomes. Therefore, it is imperious to go beyond precision medicine $[12,19]$ to treatments tailored to the unrepeatable characteristics of every single patient at each moment of his life.

This report presents the Gene Master Regulator (GMR) method [20, 21] to identify the most legitimate targets for a gene therapy that would selectively kill the cancer cells 
from a tissue [22]. Although we present 3-gene tickets to erase three distinct cancer clones in the profiled prostate, the method could in principle be used for as many as relevant cancer nodules are found in the tissue. The GMR of a cell phenotype in a tissue is the gene whose strictly controlled expression regulates the major functional pathways by coordinating the expressions of most of their genes. Owing to the uniqueness and dynamics of the transcriptome, each cell phenotype of the tumor has a distinct gene hierarchy, the GMR approach personalizing the gene treatment for each patient to destroy as many as possible cancer nodules of the affected prostate.

The GMR method is based on the Genomic Fabric Paradigm (GFP) [23] that takes advantage of profiling thousands genes at a time on multiple biological replicates. GFP assigns to each quantified gene the independent variables: average expression level (AVE), relative expression variability (REV), and correlation (COR) with expression of each other gene quantified in that group of samples [24]. Regardless of (microarray or RNA-sequencing) platform, adding REVs and CORs values to the traditional AVEs increases by $4-5$ orders of magnitude the amount of useful information provided by the transcriptomic study without any additional costs of the experiment.

AVE is used by all oncogenomists to determine whether that gene was up/down-regulated or turned on/off by cancer with respect to the normal tissues and in almost all publications this is the single variable considered for individual genes.

Although profiling additional biological replicas was required initially only for statistical relevance of the results, it gives us also very important clues about the cell priorities in controlling the gene expression. The biological replicas can be formally considered as cases of the same system subjected to (non-regulating) different environmental conditions, each gene's REV indicating how sensitive that gene is to slight environmental change. In all transcriptomic studies, we found genes that are very stably expressed (low REV) and genes with high expression variability (high REV) across biological replicas. Low REV indicates strong control of the expression level by cellular the homeostatic mechanisms, most likely because the right expression of that gene is critical for the cell phenotypic expression, survival, proliferation and integration in the multi-cellular tissue. By contrast, expressions of other genes are left to fluctuate (high REV) to ensure cell adaptation to the environmental continuous changes [25].

Profiling expressions of thousands genes at a time on biological replicas allows to quantify how much fluctuations in expression of one gene are correlated/coordinated with fluctuations of each other gene across biological replicas. COR analysis responds to the "Principle of Transcriptomic Stoichiometry" [25], a generalization of Dalton's Law of multiple proportions from chemistry [26], requiring coordinated expression of genes whose encoded products are linked in functional pathways.

\section{Materials and Methods}

\subsection{Prostate tissues and cell lines}

This report uses transcriptomic data generated in NYMC IacobasLab by profiling the surgically removed prostates of two men and two human prostate cancer cell lines: the androgen-sensitive LNCaP [27] and the not hormone sensitive DU145 [28]. Expression data obtained in our lab from the LNCaP cells (hereafter denoted by " $\mathrm{L}$ ") were deposited at [29] and those from the DU145 cells (hereafter denoted by " $\mathrm{D}^{\prime \prime}$ ) at [30].

Tissues were collected from a 65y black man $(1 \mathrm{GS}(4+5=) 9$ cancer nodule and 2 GS $(4+4=) 8$ nodules) as described in [31] and from a $47 y$ white man (3 cancer nodules of $4+$ $5=9$ Gleason score (GS) each). Gene expression data of the $65 \mathrm{y}$ patient (hereafter denoted as "ABCN") were deposited at [32] for the primary node " $\mathrm{A}$ " and the cancer-free margins " $\mathrm{N}$ ", and at [33] for the secondary nodes " $\mathrm{B}$ " and " $\mathrm{C}$ ", and analyzed in a recent paper [31]. The white 47y patient (hereafter denoted as "PQMZ") had prostatic adenocarcinoma involving $75 \%$ of bilateral lobes, with extensive perineural invasion, multifoci of extraprostatic extension that affected also the bilateral seminal vesicles. Gene expression data from this patient are available at [34] for the nodule " $\mathrm{M}$ " and the cancer free resec- 
tion margins " $\mathrm{Z}$ " and at [35] for the cancer nodules " $\mathrm{P}$ " and " $\mathrm{Q}$ ". The study, conducted according to the guidelines of the Declaration of Helsinki, was part of Dr. Iacobas' project approved by the Institutional Review Boards (IRB) of the New York Medical College's (NYMC) and Westchester Medical Center (WMC) Committees for Protection of Human Subjects. The approved IRB (L11,376 from 2 October 2015) granted access to frozen cancer specimens from the WMC Pathology Archives and depersonalized pathology reports, waiving the patient's informed consent.

. The experimental protocol (RNA extraction, fluorescent labeling, hybridization with the microarray, washing and scanning the chip) as well as the primary analysis of the fluorescent values (filtering, background subtraction and normalization to the median of valid spots in all profiled samples) are detailed in the Gene Expression Omnibus website hosting the deposited datasets [29, 30, 32-35].

\subsection{Transcriptomic analyses}

AVE, REV and COR values were computed to account for the not uniform numbers of spots probing redundantly numerous genes in Agilent $4 \times 44 \mathrm{k}$ human dual-color microarrays (configuration G2519F, platform GPL13497 [36]).

$A V E_{i}^{\text {(sample })}=\frac{1}{R_{i}} \sum_{k=1}^{R_{i}} \mu_{i, k}^{\text {(sample })}=\frac{1}{R_{i}} \sum_{k=1}^{R_{i}}\left(\frac{1}{4} \sum_{j=1}^{4} a_{i, k, j}^{(\text {sample })}\right)$, where:

sample = "N"," A"," B","C","Z"," P","Q"," $M ", " L ", " D$ "

$R_{i}=$ number of spots probing redundantly gene " $\mathrm{i}$ ",

$a_{i, k, j}^{(\text {sample })}=$ expression of gene " $i$ " probed by spot " $k$ " on biological replica " $j$ " in "sample"

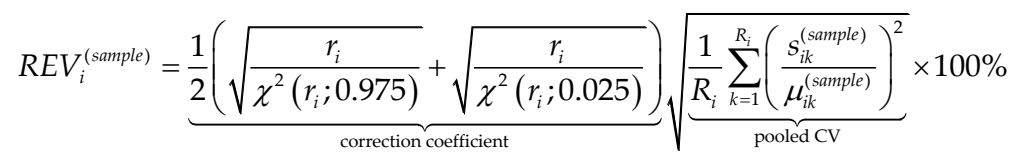

$\mu_{i k}=$ average expression of gene i probed by spot $\mathrm{k}\left(=1, \ldots, R_{i}\right)$ in the 4 biological replicas

$s_{i k}=$ standard deviation of the expression level of gene i probed by spot $\mathrm{k}$

$r_{i}=4 R_{i}-1=$ number of degrees of freedom

The correction coefficient is the mid chi-square interval estimate of the unit standard deviation and takes values from 2.15 for genes probed by one spot each to 1.05 for genes probed by 11 spots (like TP53).

$$
C O R_{i g}^{(\text {sample })}=\frac{\sum_{k_{i}=1}^{R_{i}} \sum_{k_{g}=1}^{R g}\left(\sum_{j=1}^{4}\left(a_{i, k, j}^{\text {(sample })}-A V E_{i}^{(\text {sample })}\right)\left(a_{g, k, j}^{\text {(sample }}-A V E_{g}^{(\text {sample })}\right)\right)}{\sqrt{\sum_{k_{i}=1}^{R_{i}}\left(\sum_{j=1}^{4}\left(a_{i, k, j}^{\text {(sample }}-A V E_{i}^{(\text {sample })}\right)^{2}\right) \sum_{k_{g}=1}^{R_{g}}\left(\sum_{j=1}^{4}\left(a_{g, k, j}^{\text {(sample })}-A V E_{g}^{(\text {sample })}\right)^{2}\right)}}
$$

In (3), COR $(-1 \leq \mathrm{COR} \leq 1)$ is the Pearson product-momentum correlation coefficient between the expression levels of genes " $\mathrm{i}$ " and " $\mathrm{g}$ ". For genes probed by 1 spot each, $\mathrm{p}<$ 0.05 significant synergistic/antagonistic expression was assigned if $|C O R| \geq 0.95$. If the genes are probed by 2 spots each, then significant coordination occurs for $|\mathrm{COR}| \geq 0.71$, and so on with cut-off diminishing for larger numbers of spots probing each gene [25].

REV and COR were used to determine the Gene Commanding Height (GCH) [31] that establishes the gene hierarchy in the profiled phenotype: 


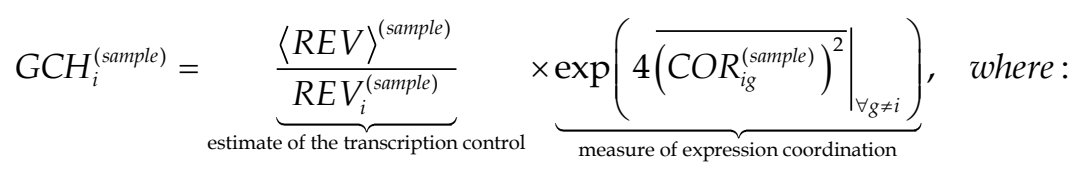

\langle\rangle$=$ median, $\overline{()^{2}}=$ average of the square values

The top gene of the hierarchy (highest GCH) is the Gene Master Regulators (GMR) of that phenotype, whose altered expression should have the largest consequences. The hierarchies of the four groups of samples were used to identify the top 3 genes whose GCH scores in the three cancer nodules are far above the corresponding scores in the cancer-free tissue.

A gene was considered as statistically $(\mathrm{p}<0.05)$ significantly regulated in a cancer nodule ("cancer") with respect to the normal tissue from the same tumor if the absolute fold-change $x$ and the $\mathrm{p}$-value $\left(p_{i}^{\text {(normal } \rightarrow \text { cancer })}\right)$ of the heteroscedastic $t$-test of the means equality in the two regions satisfied the composite criterion (5). Our cut-off of the absolute fold-change considers the combined effects of the biological variability and technical noise, providing a much accurate criterion for expression regulation than any other arbitrary $(1.5 x, 2.0)$ fold-change requirement.

$$
\begin{aligned}
& \left\{\begin{array}{l}
\left|x_{i}^{(\text {normal } \rightarrow \text { cancer })}\right|>C U T_{i}^{(\text {normal } \rightarrow \text { cancer })}=1+\frac{1}{100} \sqrt{2\left(\left(R E V_{i}^{(\text {normal })}\right)^{2}+\left(R E V_{i}^{(\text {cancer })}\right)^{2}\right)} \\
p_{i}^{(\text {normal } \rightarrow \text { cancer })}<0.05
\end{array}\right. \\
& \text { where: } \text { cancer }=" A ", " B ", " C ", " M ", " P ", " Q " \text { normal = "N","Z" }
\end{aligned}
$$

$$
x_{i}^{\text {(normal } \rightarrow \text { cancer })} \equiv \begin{cases}\frac{\mu_{i}^{(\text {cancer })}}{\mu_{i}^{\text {(normal })}} & , \text { if } \mu_{i}^{(\text {cancer })}>\mu_{i}^{(\text {normal })} \\ -\frac{\mu_{i}^{(\text {normal })}}{\mu_{i}^{(\text {cancer })}} & , \text { if } \mu_{i}^{(\text {cancer })}<\mu_{i}^{(\text {normal })}\end{cases}
$$

The p-value was computed with Bonferroni correction for multiple testing [37] in the case of several spots probing redundantly the same gene.

Instead of the uniform \pm 1 contribution to the altered transcriptome used in the traditional percentage measure of the significantly up/down-regulated genes, we consider the Weighted Individual gene Regulation (WIR). WIR analysis is not limited to the significantly regulated genes but applied to any gene. WIR was used to compute the Weighted Pathway Regulation (WPR) to average the contributions of all genes assigned to that functional pathway:

$$
\begin{aligned}
& W R_{i}^{(\text {normal } \rightarrow \text { cancer })}=A V E_{i}^{(N)} \frac{x_{i}^{(\text {normal } \rightarrow \text { cancer })}}{\left|x_{i}^{(N \rightarrow \text { cancer })}\right|}\left(\left|x_{i}^{(\text {normal } \rightarrow \text { cancer })}\right|-1\right)\left(1-p_{i}^{(\text {normal } \rightarrow \text { cancer })}\right) \\
& W P R_{\Gamma}^{(\text {normal } \rightarrow \text { cancer })}=\overline{\left.W_{i}^{(\text {normal } \rightarrow \text { cancer })}\right|_{i \in \Gamma}} \quad, \quad \Gamma=\text { functional pathaway }
\end{aligned}
$$

\section{Results}

\subsection{Overview}

In total, we quantified expression of 14,203 distinct unigenes in all three cancer nodules and the surrounding cancer-free tissue from the surgically removed prostate of the "PQMZ" man. The 403,620,854 (total number of AVE, REV and COR) values resulted from this experiment illustrate the analyses below. In order to show the uniqueness of the 1-2-3 ticket, we used also the expression values in the three cancer nodules and cancer-free surroundings of the "ABCN" man (14,908 genes), in the LNCaP cells $(15,278$ genes) and in the DU145 cells (16,126 genes). 
Table 1 presents the 3 genes with the largest expressions in each of the four profiled regions " $\mathrm{P}$ ", " $\mathrm{Q}$ ", " $\mathrm{M}$ ", and " $\mathrm{Z}$ ". Remarkably, as in the other profiled surgically removed prostate (reported in [31]), RPL13 was among the 3 genes with the largest expressions in all four regions, and in both patients down-regulated in the cancer nodules with respect to the corresponding normal tissues. The robust down-regulation of RPL13 in all six cancer nodules (by $-1.70 \mathrm{x} /-1.38 \mathrm{x} /-1.36 \mathrm{x}$ in " $\mathrm{P}$ " $/$ " $\mathrm{Q}$ " $/$ " $\mathrm{M}$ " vs " $\mathrm{Z}$ " and by $2.15 \mathrm{x} /-1.30 \mathrm{x} /-1.50 \mathrm{x}$ in " $\mathrm{A}$ "/" $\mathrm{B}$ "/" $\mathrm{C}$ " vs " $\mathrm{N}$ ") explains the reduced immune response in cancer. Our results add new evidence about the extraribosomal roles of RPL13, particularly in activating the innate response [38].

\begin{tabular}{|l|l|r|r|r|r|}
\hline Gene & Description & AVE-P & AVE-Q & AVE-M & AVE-Z \\
\hline CYTB & mitochondrially encoded cytochrome b & 231 & 237 & 186 & 266 \\
\hline RPL13 & ribosomal protein L13 & 215 & 2365 & 269 & 366 \\
\hline ACTG2 & actin, gamma 2, smooth muscle, enteric & 204 & 126 & 119 & 325 \\
\hline NPY & neuropeptide Y & 76 & 471 & 10 & 123 \\
\hline RPL13 & ribosomal protein L13 & 215 & 265 & 269 & 366 \\
\hline RPL7A & ribosomal protein L7a & 106 & 310 & 141 & 241 \\
\hline RPL13 & ribosomal protein L13 & 215 & 265 & 269 & 366 \\
\hline ZNF865 & zinc finger protein 865 & 182 & 267 & 203 & 292 \\
\hline PQLC2 & PQ loop repeat containing 2 & 172 & 179 & 199 & 203 \\
\hline RPL13 & ribosomal protein L13 & 215 & 265 & 269 & 366 \\
\hline ACTG2 & actin, gamma 2, smooth muscle, enteric & 204 & 126 & 119 & 325 \\
\hline MYH11 & myosin, heavy chain 11, smooth muscle & 137 & 101 & 139 & 307 \\
\hline
\end{tabular}

Table 1: The 3 genes with the largest average expression levels (AVE) in each of the four profiled regions of the "PQMZ" patient. The largest 3 AVE values in each phenotype are on grey background.

Table 2 lists 3 genes with the most (low REV) and the least (high REV) controlled expression in each of the four profiled regions " $\mathrm{P}$ ", "Q", " $\mathrm{M}$ ", and " $\mathrm{Z}$ ".

\begin{tabular}{|l|l|r|r|r|r|}
\hline Gene & Description & REV-P & REV-Q & REV-M & REV-Z \\
\hline FKBP9 & FKBP prolyl isomerase 9 & 0.32 & 8.80 & 10.87 & 9.27 \\
\hline ZBTB2 & zinc finger and BTB domain containing 2 & 0.50 & 12.39 & 5.03 & 16.51 \\
\hline NUBPL & nucleotide binding protein-like & 0.69 & 12.19 & 5.48 & 10.73 \\
\hline LINC00294 & long intergenic non-protein coding RNA 294 & 186.26 & 167.79 & 9.72 & 9.11 \\
\hline RNF180 & ring finger protein 180 & 176.24 & 88.31 & 13.00 & 24.39 \\
\hline ZNF514 & zinc finger protein 514 & 173.86 & 104.05 & 18.43 & 9.59 \\
\hline TBRG4 & transforming growth factor beta regulator 4 & 11.07 & 0.59 & 1.56 & 8.06 \\
\hline DNAJC24 & DnaJ (Hsp40) homolog, subfamily Cr, member 24 & 11.62 & 0.85 & 7.19 & 4.16 \\
\hline UBE3B & ubiquitin protein ligase E3B & 5.32 & 1.00 & 6.51 & 9.46 \\
\hline SCGB1A1 & secretoglobin, family 1A, member 1 & 117.24 & 192.39 & 30.93 & 79.71 \\
\hline ACTA1 & actin, alpha 1, skeletal muscle & 128.46 & 188.64 & 16.90 & 100.97 \\
\hline TCAP & titin-cap & 41.99 & 185.20 & 12.58 & 118.09 \\
\hline TMEM186 & transmembrane protein 186 & 9.32 & 20.45 & 0.28 & 12.49 \\
\hline
\end{tabular}




\begin{tabular}{|c|c|c|c|c|c|}
\hline NDUFA6-AS1 & NDUFA6 antisense RNA 1 (head to head) & 28.15 & 8.46 & 0.50 & 15.82 \\
\hline LMAN2L & lectin, mannose-binding 2-like & 8.05 & 8.20 & 0.52 & 8.00 \\
\hline$U B E 2 I$ & ubiquitin-conjugating enzyme E2I & 22.29 & 34.84 & 160.31 & 195.73 \\
\hline ZNF16 & zinc finger protein 16 & 11.25 & 10.56 & 164.26 & 89.80 \\
\hline OAZ2 & ornithine decarboxylase antizyme 2 & 19.57 & 12.15 & 182.91 & 131.26 \\
\hline COPS5 & COP9 signalosome subunit 5 & 51.46 & 27.83 & 7.37 & 0.12 \\
\hline$A R P C 5 L$ & actin related protein $2 / 3$ complex, subunit 5 -like & 19.90 & 22.18 & 7.13 & 0.14 \\
\hline$D A Z A P 1$ & DAZ associated protein 1 & 7.14 & 18.87 & 3.84 & 0.22 \\
\hline OSCP1 & organic solute carrier partner 1 & 3.82 & 11.27 & 54.45 & 140.84 \\
\hline MBD6 & methyl-CpG binding domain protein 6 & 16.58 & 27.71 & 93.02 & 162.48 \\
\hline UBE2I & ubiquitin-conjugating enzyme E2I & 22.29 & 34.84 & 160.31 & 195.73 \\
\hline
\end{tabular}

Table 2: The most 3 stably (low REV, darker grey background) and the most 3 variably (high REV, lighter grey background) expressed genes in each of the four profiled regions "P", "Q", "M", and "Z".

Table 2 has some very interesting results. First, each of the four regions appears to have different priorities in controlling the transcripts' abundances. Our results indicate that the most controlled genes are critical for preserving the phenotype. Thus, FKBP9, the most controlled gene in nodule " $\mathrm{P}$ ", is known for promoting malignant behavior of glioblastoma cells [39] and poor prognosis of PCa patients [40]. TBRG4, the most stably expressed gene in " $Q$ ", was reported as actively involved in myeloma [41], squamous carcinoma [42], osteosarcoma [43], glioblastoma [44], leukemia [45] and lung cancer [46]. The list of stably expressed genes includes also a long noncoding RNA, NDUFA6-AS1, identified recently as a biomarker for the prognostic of thyroid cancer [47]. We believe that the strict control of the expression of COPS5 is related to its role in controlling the progression of PCa [48].

Table 3 presents the 3 genes with the largest positive and the 3 genes with the largest negative contributions to the transcriptomic alterations in each of the three cancer nodules. While some genes were regulated the same way in all three nodules (CNN1, RNA28S5, RLN1, ACTG2), others not regulated in all nodules (RPS8, MARC1, PSCA) or even oppositely regulated in one nodule than in the other two (NPY, IGKC, IGHG1, SNORD3B-1).

\begin{tabular}{|l|l|r|r|r|}
\hline Gene & Description & WIR-P & WIR-Q & WIR-M \\
\hline PSCA & prostate stem cell antigen & $\mathbf{5 4}$ & 138 & 0 \\
\hline KLK12 & kallikrein-related peptidase 12 & $\mathbf{4 0}$ & 121 & 0 \\
\hline BASP1 & brain abundant, membrane attached signal protein 1 & $\mathbf{3 2}$ & 39 & 0 \\
\hline RPS8 & ribosomal protein S8 & -383 & 0 & -123 \\
\hline CNN1 & calponin 1, basic, smooth muscle & -403 & -680 & -568 \\
\hline RNA28S5 & RNA, 28S ribosomal 5 & -604 & -314 & -26 \\
\hline MARC1 & mitochondrial amidoxime reducing component 1 & 0 & $\mathbf{9 1 8 0}$ & 0 \\
\hline NPY & neuropeptide Y & -50 & 348 & -1345 \\
\hline PSCA & prostate stem cell antigen & 54 & $\mathbf{1 3 8}$ & 0 \\
\hline CNN1 & calponin 1, basic, smooth muscle & -403 & -680 & -568 \\
\hline
\end{tabular}




\begin{tabular}{|l|l|r|r|r|} 
LTF & lactotransferrin & -301 & -1682 & 22 \\
\hline RLN1 & relaxin 1 & -86 & -2658 & -46 \\
\hline IGKC & immunoglobulin kappa constant & -51 & -144 & $\mathbf{6 0}$ \\
\hline IGHG1 & immunoglobulin heavy constant gamma 1 & -29 & -83 & $\mathbf{5 2}$ \\
\hline SNORD3B-1 & small nucleolar RNA, C/D box 3B-1 & -3 & -35 & 49 \\
\hline ACTG2 & actin, gamma 2, smooth muscle, enteric & -170 & -514 & -561 \\
\hline CNN1 & calponin 1, basic, smooth muscle & -403 & -680 & -568 \\
\hline NPY & neuropeptide Y & -50 & 348 & -1345 \\
\hline
\end{tabular}

Table 3 The 3 genes with the largest positive and negative contributions to the transcriptomic alterations in the cancer nodules of the "PQMZ" patient.

\subsection{Independent variables}

Figure 1 serves as an example of the independency of AVE, REV and COR for the first 50 alphabetically ordered genes involved in the mTOR signaling [49] in the cancer nodules " $\mathrm{P}$ ", " $\mathrm{Q}$ ", " $\mathrm{M}$ ", and the normal surrounding tissue " $\mathrm{Z}$ ") of the white patient prostate. Panel (c) presents the expression coordination with MTOR (mechanistic target of rapamycin (serine/threonine kinase)). Although MTOR gene and mTOR signaling pathway were selected for their roles in the development, proliferation and migration of cancer cells [50], any other subset of genes would confirm the independence of the AVE, REV and COR characteristics.

Within this selection, genes such as ATPase, $\mathrm{H}+$ transporting, lysosomal 13kDa, V1 subunit G2 (ATP6V1G2) have very low expression $(\mathrm{AVE}=0.14$ in " $\mathrm{Q}$ ") and genes like ATPase, $\mathrm{H}+$ transporting, lysosomal $14 \mathrm{kDa}$, V1 subunit $\mathrm{F}$ (ATP6V1F) with much higher expression (34.5 in " $\mathrm{Q}$ "). Likewise, there are very stably (e.g. DEP domain containing 5 $(D E P D C 5), \mathrm{REV}=0.25 \%$ in " $\mathrm{Z}$ ") and very unstably (e.g. frizzled class receptor 10 (FZD10), REV $=87.48 \%$ in " $\mathrm{Q}$ ") expressed genes.

In addition to the clear independence of the three variables, of note are also the differences among the three equally histopathologically ranked cancer nodules from the same prostate, proving again the transcriptomic heterogeneity of the PCa. The nodules transcriptomes differ not only as expression levels of individual genes but also in their expression variability (indicating different strengths of controlling mechanisms) and expression coordination (distinct gene networking in pathways). For instance, FZD10, known for its role in breast cancer [51] was very unstably expressed in " $Q$ " and " $\mathrm{P}$ " (REV $=59.96 \%)$, but enough stably expressed in " $\mathrm{M}$ " (REV $=6.16 \%)$. These values suggest that the right expression of FZD10 was more important for the "M" cells than for the "P" and "Q" cells. Also, eukaryotic translation initiation factor 4E (EIF4E) was synergistically expressed with MTOR in "Q", but antagonistically expressed with MTOR in " $\mathrm{P}$ " and "M", meaning that EIF4E works as an activator of MTOR in " $\mathrm{Q}$ " but as an inhibitor in " $\mathrm{P}$ " and " $\mathrm{M}$ ", which indicates that targeting EIF4E may have opposite clinical results [52]. 


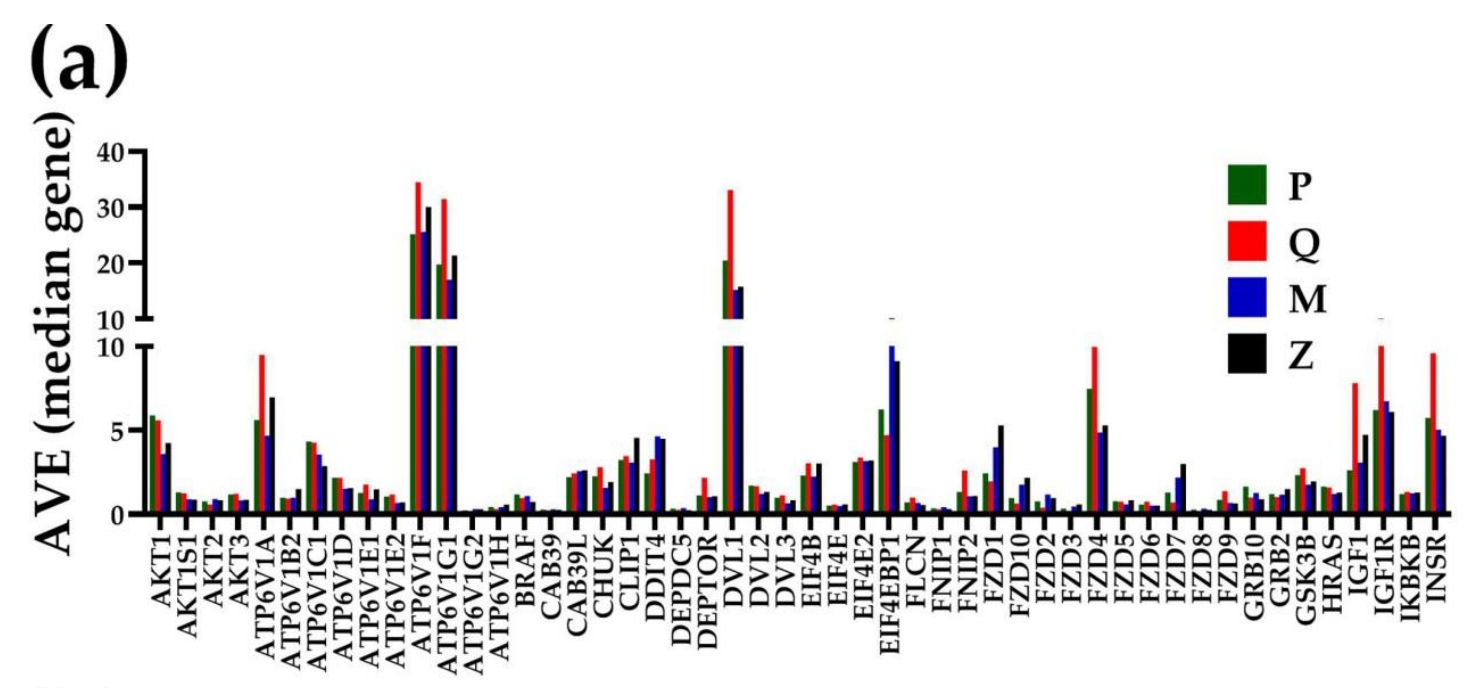

(b)

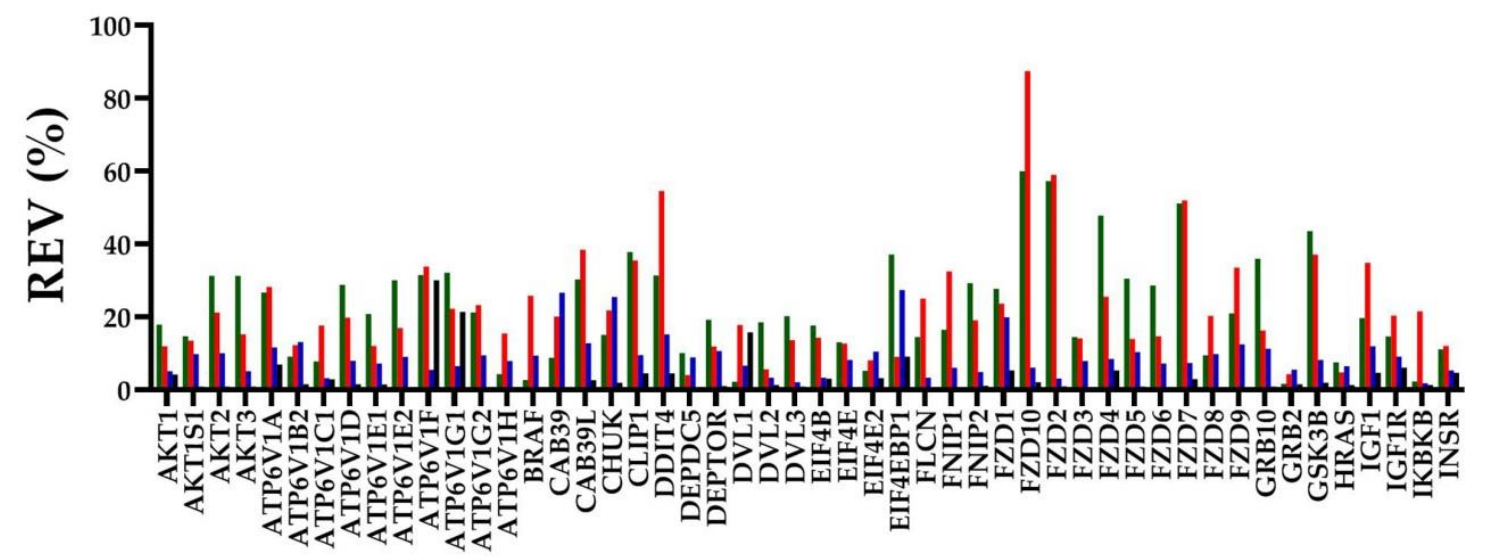

(c)

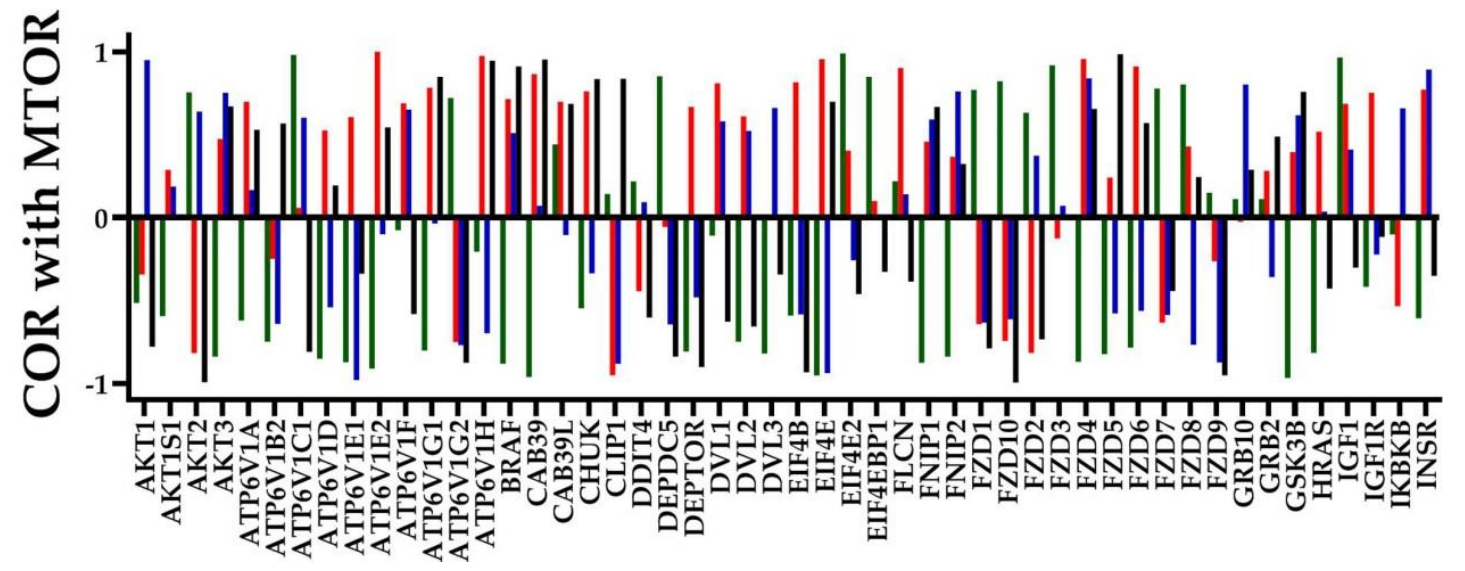

Figure 1. Independent transcriptomic characteristics of the first 50 alphabetically ordered genes of the mTOR signaling pathway in the thre cancer nodules (" $\mathrm{P}$ ", " $\mathrm{Q}$ ", “ $\mathrm{M}$ ") and the surrounding normal prostate tissue ("Z"). (a) Average expression levels (AVE) in expressions of the median gene; (b) Relative Expression Variability (REV); (c) Expression correlation (COR) with MTOR. 
Figure 2 presents the regulation of the first 50 alphabetically ordered mTOR signaling genes in the three cancer nodules with respect to the cancer-free surrounding tissue. The regulation of genes is presented as uniform \pm 1 contribution (as in the percentage of significantly up/down regulated genes, expression ratio " $x$ " and weighted individual

(a) gene regulation, "WIR".

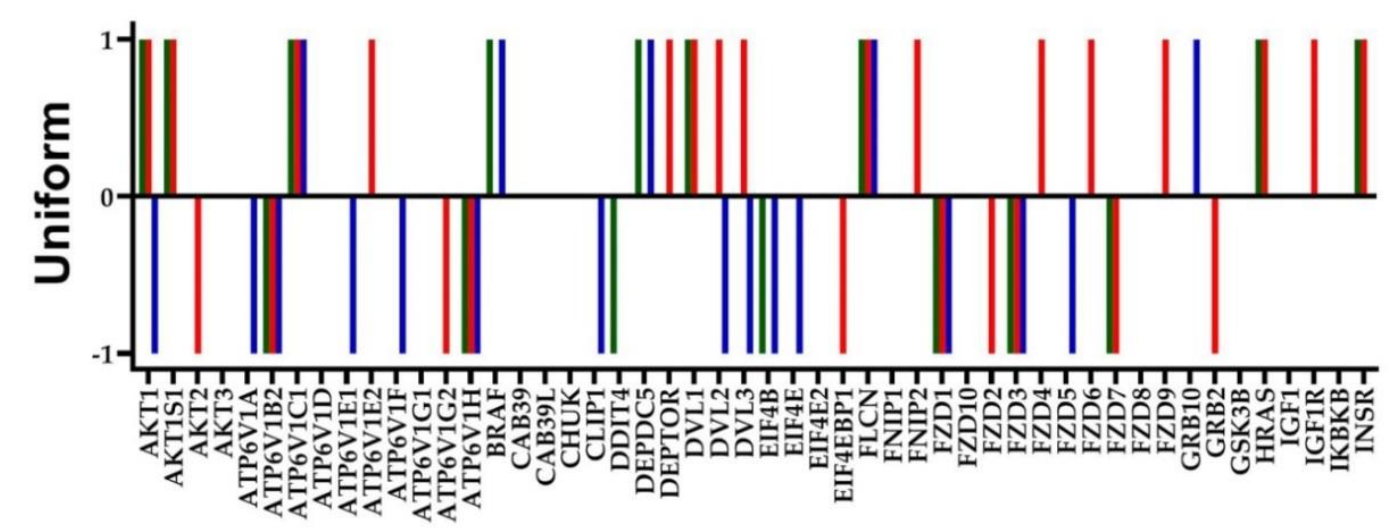

\section{(b)}

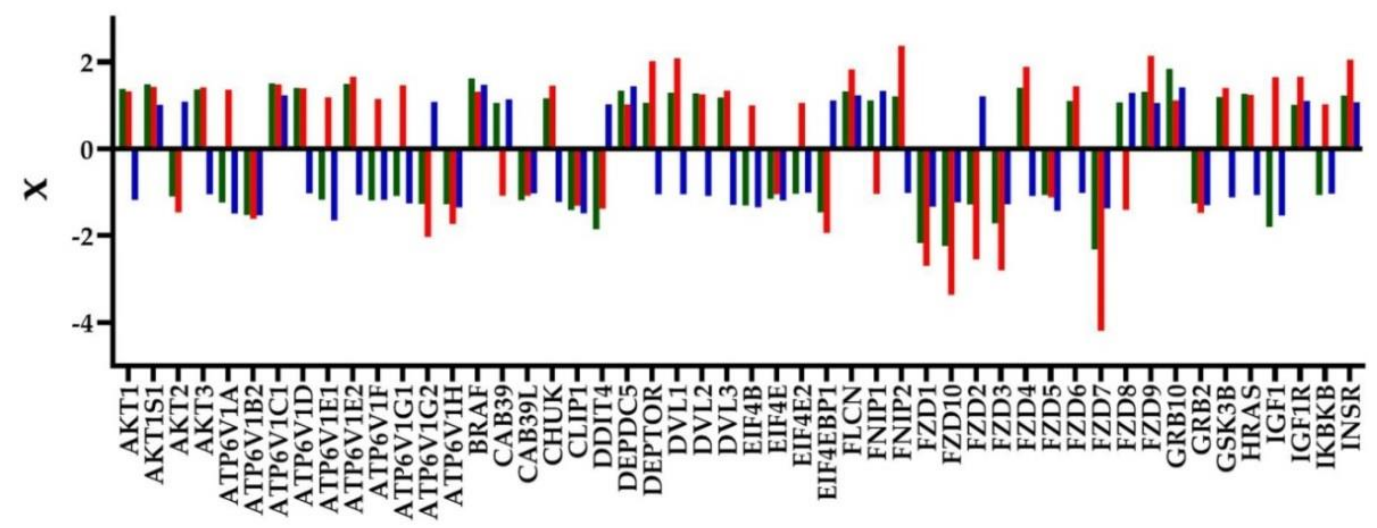

\section{(c)}

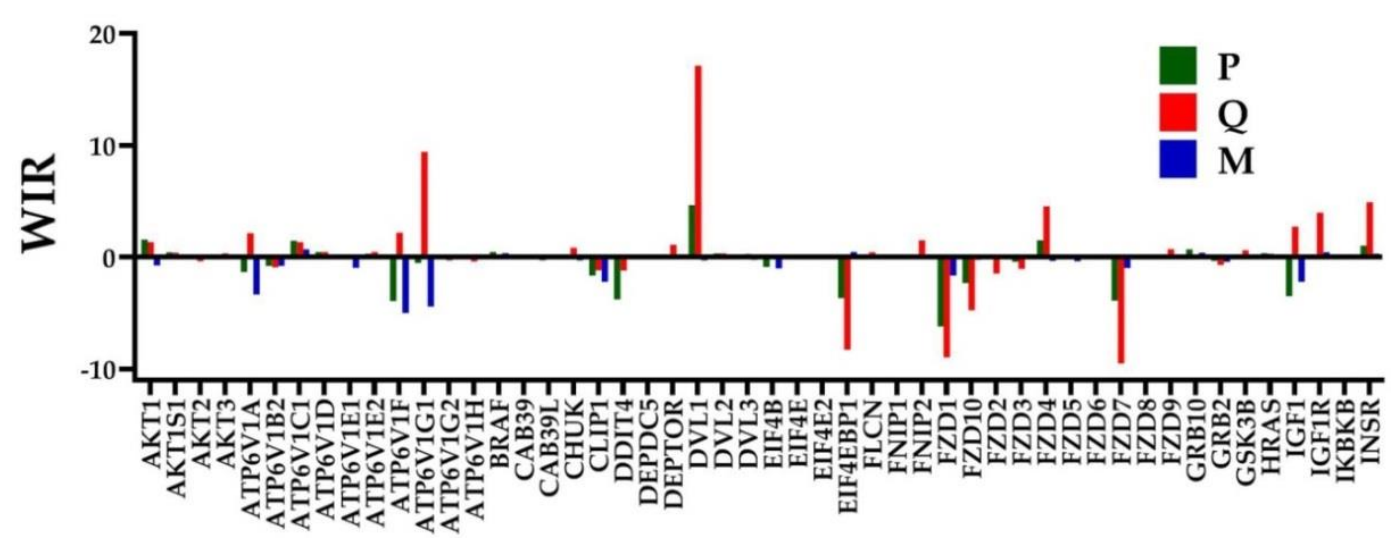

Figure 2. Regulation of the first 50 alphabetically ordered mTOR signaling genes. (a) As uniform \pm 1 contribution. (b) Expression ratio " $x$ " (negative for down-regulation. (c). Weighted Individual gene Regulation "WIR". Note the differences among the nodules.

The power of WIR to discriminate the genes according to their contribution is outstanding. For instance, DEPTOR (DEP domain containing MTOR-interacting protein) 
and DVL1 (dishevelled segment polarity protein 1) have similar expression ratios in " $\mathrm{Q}$ " (2.03x and 2.09x) but substantially different WIRs (1.10 and 17.13).

Remarkably, although most of the significant regulations go the same way in all three nodules (ATP6V1AB2, ATP6V1C1, ATV6V1H, FLCN, FZD1, FZD3), there are also opposite regulations ( $A K T 1, D V L 2, D V L 3)$. The significant opposite regulations presented in Table 3 and Figure 2 indicate that, even within the same tumor, each cancer nodule has its own "transcriptomic signature". Therefore, it makes no sense to continue using the transcriptomic signature in classifying the PCas.

\subsection{Tumor heterogeneity of gene networks}

Figure 3 presents the expression coordinations of $A K T 2$ (v-akt murine thymoma viral oncogene homolog 2), with its partners central to the prostate cancer development [53] in all four profiled regions from the patients "PQMZ" and "ABCN". Fig.3 presents also the coordinations of MTOR with mTORC1 (RAPTOR, ACT1S1, DEPTOR, MLST8, TELO2 and TTI1) and MTORC2 (RICTOR, MAPKAP1, PRR5, DEPTOR, MLST8, TELO2 and TTI1) partners [49] in the same regions.

Of note are the substantial differences in both expression regulation with respect to the surrounding normal tissue and in expression coordination not only between the two patients but also among the cancer nodules of each patient. These results extend the notion of transcriptomic heterogeneity of the tumor to the formation of gene networks that could be even more important for the cell behavior than the heterogeneity of the gene expression levels.

Interestingly, MTOR is not significantly coordinately expressed with any of its MTORC1 and MTORC2 alleged partners in the nodules " $\mathrm{Q}$ ", " $\mathrm{M}$ ", " $\mathrm{B}$ " and " $\mathrm{C}$ ", indicating major remodeling of the mTOR signaling in these cancer clones. Altogether, the differences in gene networking among the profiled groups of samples show that the pathways built by KEGG and other pathway analysis software are not universal and can be used only as a general reference. 


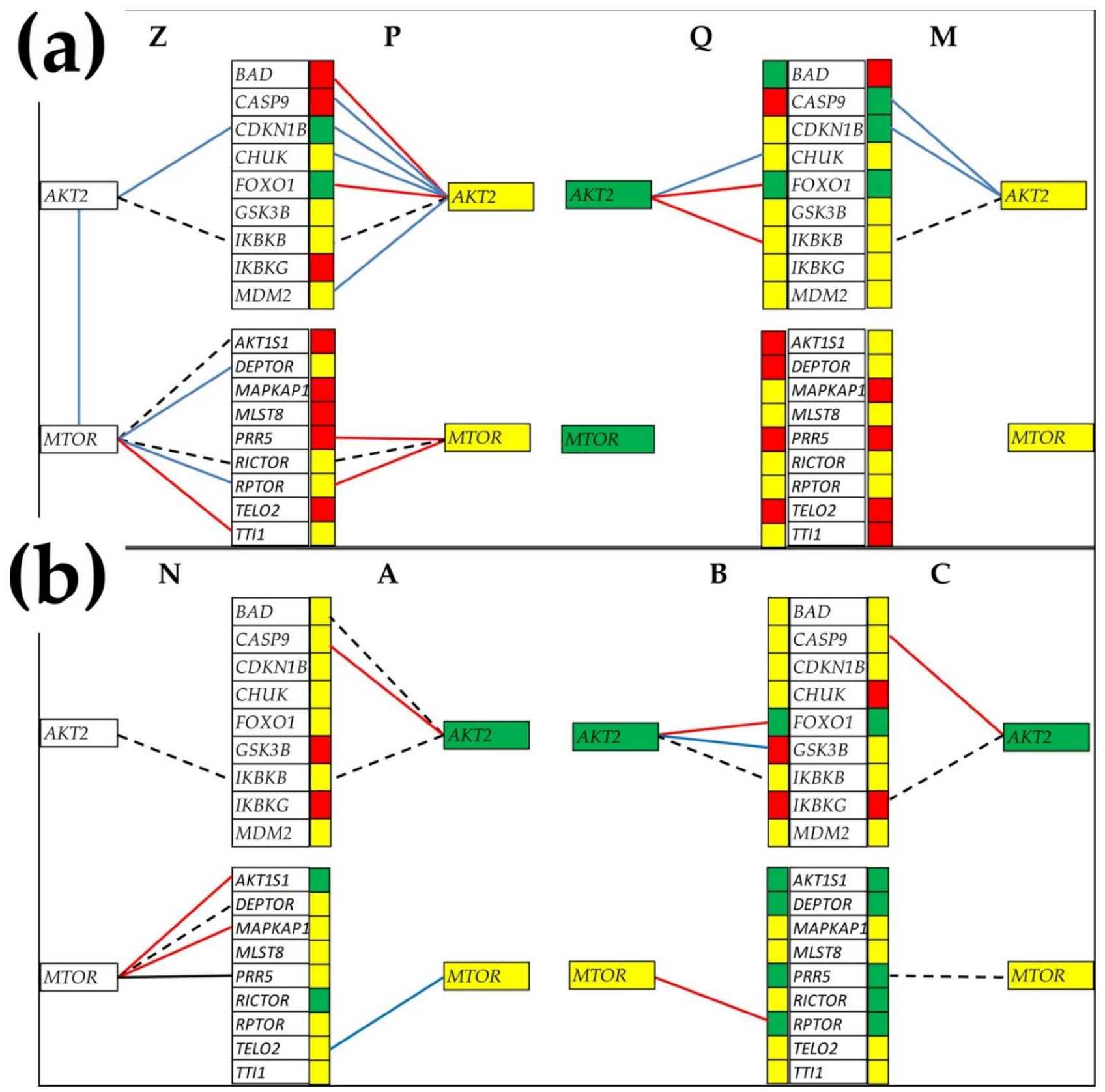

Figure 3 Expression coordinations of $A K T 2$ with its partners, central to the prostate cancer development, and the coordinations of MTOR with its partners from mTORC1 and mTORC2 in the four profiled regions of the: (a) "PQMZ" patient; (b) the "ABCN" patient. A continuous red/blue line indicates a statistically $(p<0.05)$ significant synergistic/antagonistic expression of the linked gene, while a dashed black line indicates a statistically $(p<0.05)$ significant independent expression of the paired genes. Missing lines mean lack of statistical significance of the expression coordination between the two genes. Red/green background specifies significant up/down-regulation of that gene in the indicated cancer nodule (" $\mathrm{P}^{\prime}$, , $\mathrm{Q}$ ", , "M", " $\mathrm{A}$ ", " $\mathrm{B}$ ", " $\mathrm{C}$ ”) with respect to the corresponding cancer-free surrounding tissue (" $\mathrm{Z}$ " or " $\mathrm{N}$ "), while yellow background means that the expression difference was not significant according to our composite criterion.

\subsection{Gene Master Regulators}

Figure 4 presents the GMRs of all the profiled regions from the two patients and the two cancer cell lines. For each GMR, the graph shows the GCH scores in all profiled sample types. Note that each group of samples has a distinct GMR and the substantial 
difference between the GCH score in the region the GMR commands and in the other regions from the same tumor. For instance, FKBP9, the GMR of the region " $\mathrm{P}$ " has the GCHs: 158.86 (in "P"), but 3.66 (in “Q"), 1.96 (in "M"), 2.59 (in "Z"), 8.24 (in "A"), 2.52 (in “B"), 2.36 (in " $\left.\mathrm{C}^{\prime \prime}\right), 1.47$ (in " $\mathrm{N}$ "), 7.46 (in " $\mathrm{L}$ ") and 16.59 in "( $\left.\mathrm{D}^{\prime \prime}\right)$. The large difference between the GCH scores in the cancer clone and the normal tissue indicates that manipulation of that gene would have major transcriptomic consequences in the cancer but practically nothing in the healthy tissue. This observation makes the GMR approach suitable to design cancer gene therapies.

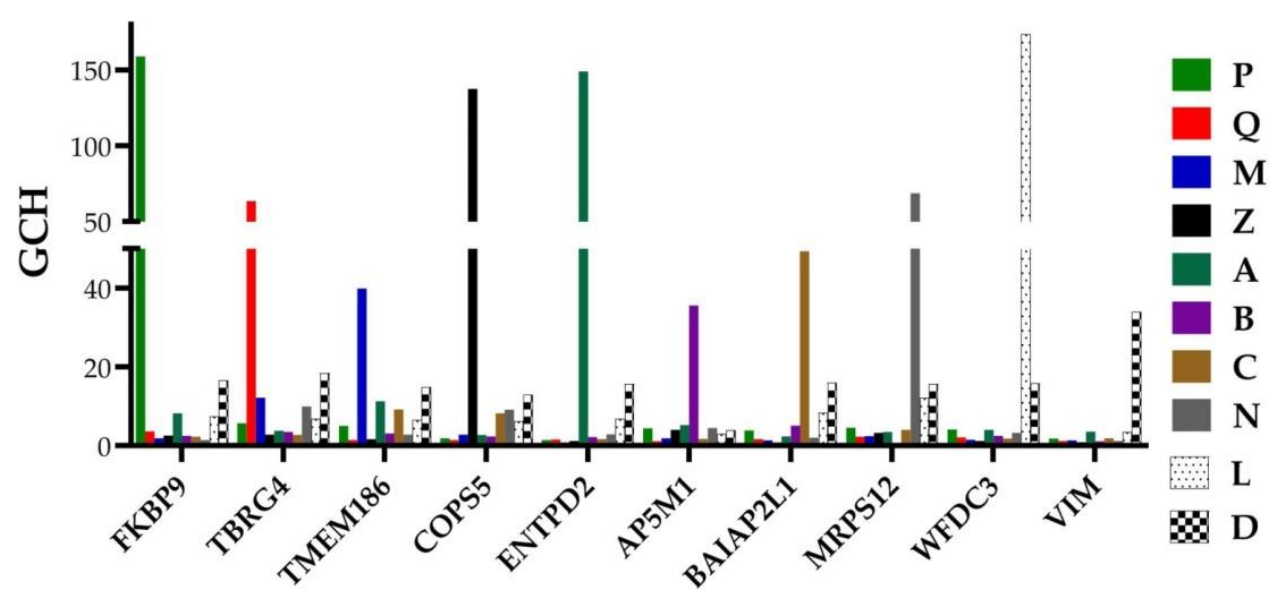

Figure 4 The GMRs of the profiled regions from the prostates of the "PQMZ" and "ABCN" patients, and from the cancer cell lines " $\mathrm{L}$ " and " $\mathrm{D}$ ". Note that the GCH scores in the other samples are substantially lower that in the sample commanded by the GMR.

The GMRs of the cancer nodules are not necessary regulated with respect to the normal tissue, but as evident from Table 2, they are among the most stably expressed genes in that region. The expression level of the GMR is allowed to fluctuate within a very narrow interval because it regulates expression of numerous other genes. For instance, $F K B P 9$, the GMR of " $\mathrm{P}$ ", was similarly down-regulated in all three cancer nodules: $\mathrm{x}=-1.52(\mathrm{WIR}=-7.44)$ in " $\mathrm{P}$ ", $\mathrm{x}=-1.59(\mathrm{WIR}=-8.51)$ in " $\mathrm{Q}$ ", and $\mathrm{x}=-1.49(\mathrm{WIR}=-6.97)$ in "M". TBRG4, the GMR of " $\mathrm{Q}$ ", was up-regulated in " $\mathrm{P}$ " $(\mathrm{x}=1.25$, WIR = 0.46) and " $\mathrm{Q}$ " $(\mathrm{x}=$ 1.73 , WIR =1.39) but not in "M", while TMEM186 the GMR of " $\mathrm{M}$ ", was not regulated in any of the profiled cancer nodule. ENTPD2, the GMR of " $\mathrm{A}$ ", was not regulated in " $\mathrm{A}$ ", but up-regulated in " $\mathrm{B}$ " and " $\mathrm{C}$ ", $A P 5 M 1$, the GMR of " $\mathrm{B}$ ", was up-regulated in " $\mathrm{B}$ " but not regulated in either " $\mathrm{A}$ " or " $\mathrm{C}$ ", while BAIAP2L1, the GMR of " $\mathrm{C}$ ", was up-regulated in " $B$ " and " $C$ ", but not in " $A$ ".

\subsection{What experimental manipulation of the GMR would do to the cancer nodule's metabolism?}

We used our software \#PATHWAY\# [22] to identify all KEGG pathways [54] that include genes with statistically significant synergistic/antagonistic expression correlation with the GMR in each profiled cancer nodule. In all cancer nodules from both patients, the most significantly correlated genes with the GMR were from the metabolic pathways, indicating that targeting the GMR would have most dramatic consequences on the cell metabolism.

Figure 5 presents the significantly synergistically and antagonistically expressed genes with the corresponding GMR in each of the nodules " $\mathrm{P}$ ", " $\mathrm{Q}$ " and " $\mathrm{M}$ " of the "PQMZ" patient, and what one might expect from the significant manipulation of the GMR expression. Thus, by therapeutically increasing the expression of FKBP9 (down-regulated in " $\mathrm{A}$ " with respect to " $\mathrm{Z}$ "), the expressions of FKBP9 synergistically expressed partner genes in "A" would be pushed up, while the antagonistically expressed ones will be pushed down. Although, the proposed therapeutic overexpression will restore the normal expression of FKBP9 in all three cancer nodules, while 
up-regulating it in " $\mathrm{Z}$ ", it would have significant consequences only on " $\mathrm{P}$ ", owing to the low FKBP9 GCH scores in the other three regions. Large metabolic disturbances on the respective commanded cancer nodules but not in the other regions are also expected by knocking down TBRG4 and TMEM186, as illustrated in panels (b) and (c).
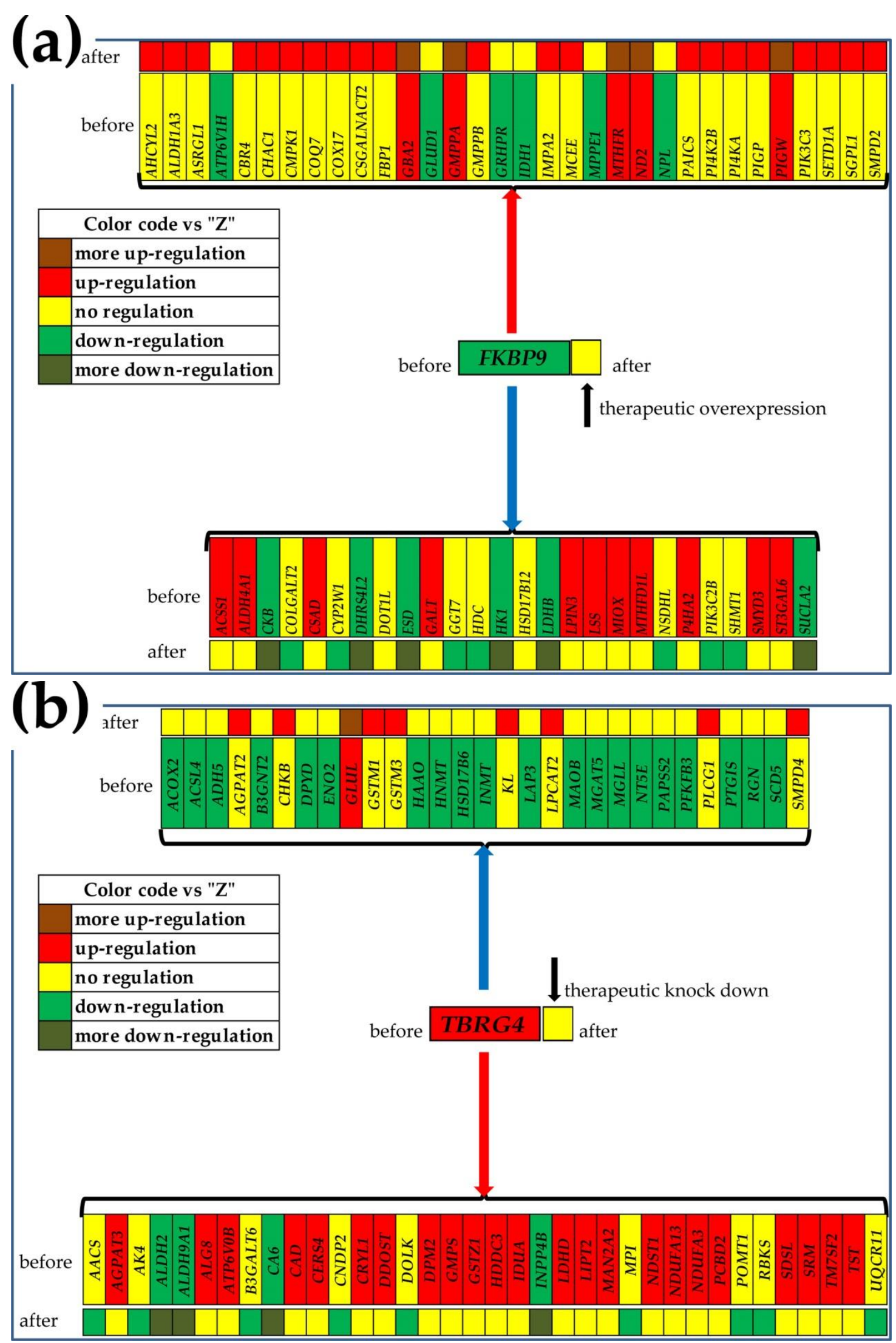


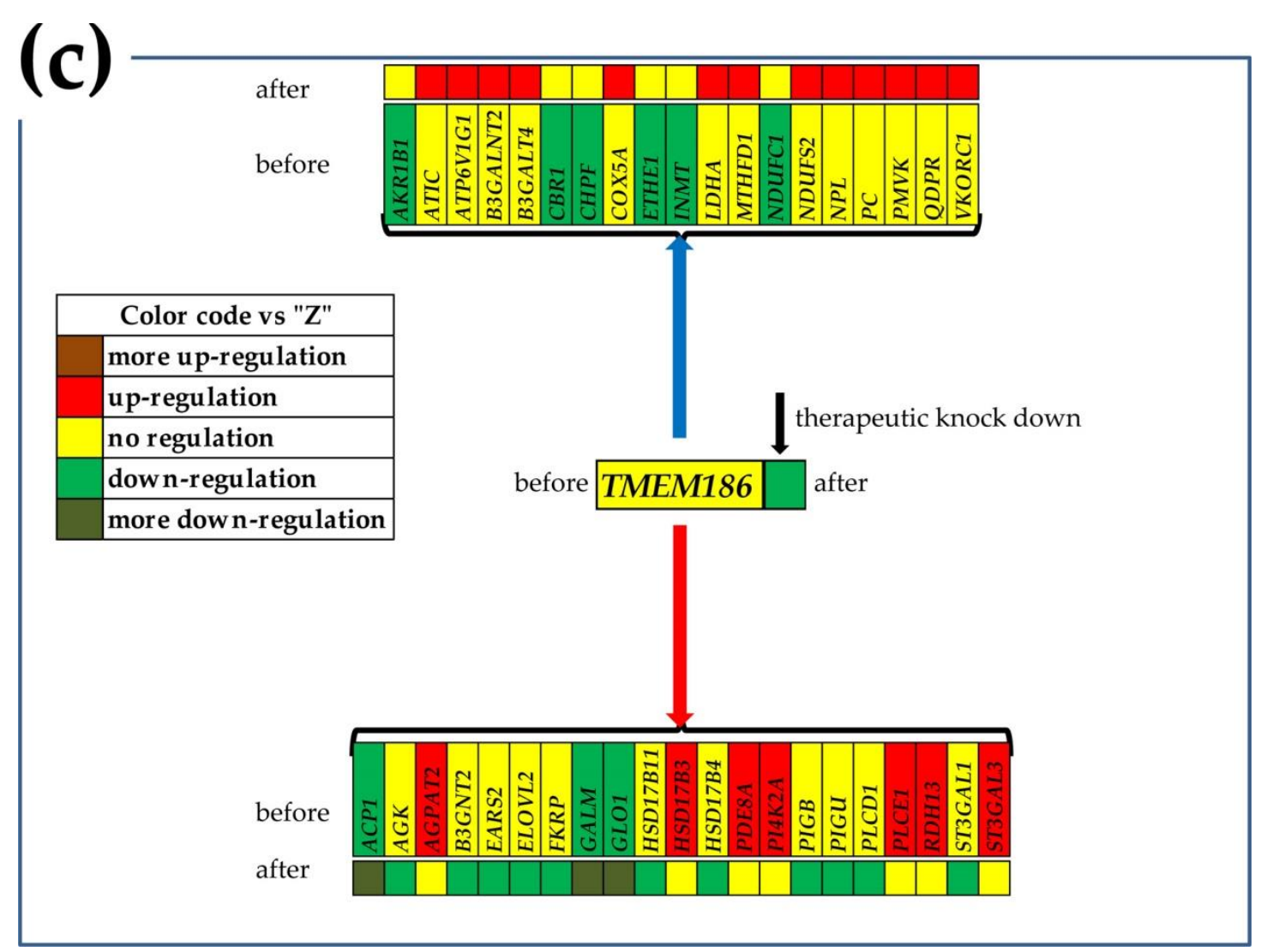

Figure 5 The significantly synergistically and antagonistically expressed metabolic genes with the corresponding GMR in the nodules: (a) "P", (b) "Q" and (c) " $\mathrm{M}$ " of the "PQMZ" patient, and the predicted regulations after the therapeutic alteration of the GMR. The $\mathrm{red} / \mathrm{blue}$ arrow indicates the genes synergistically/antagonistically expressed with the GMR in that node. Gene symbol background indicates the status of that gene in the mentioned cancer nodule with respect to the surrounding normal tissue " $\mathrm{Z}$ " before (observed) and after the treatment (predicted). Note the different regulations of the metabolic genes in the cancer nodules.

Figure 6 presents the significantly synergistically and antagonistically expressed genes with the corresponding GMR in each of the nodules " $\mathrm{A}$ ", " $\mathrm{B}$ " and " $\mathrm{C}$ " of the "ABCN" patient, and what one might expect from the significant manipulation of the GMR expression. Of note are again the different regulations of the metabolic genes in the cancer nodules of the same tumor as well between the two tumors (compare with Fig. 5 above).. 


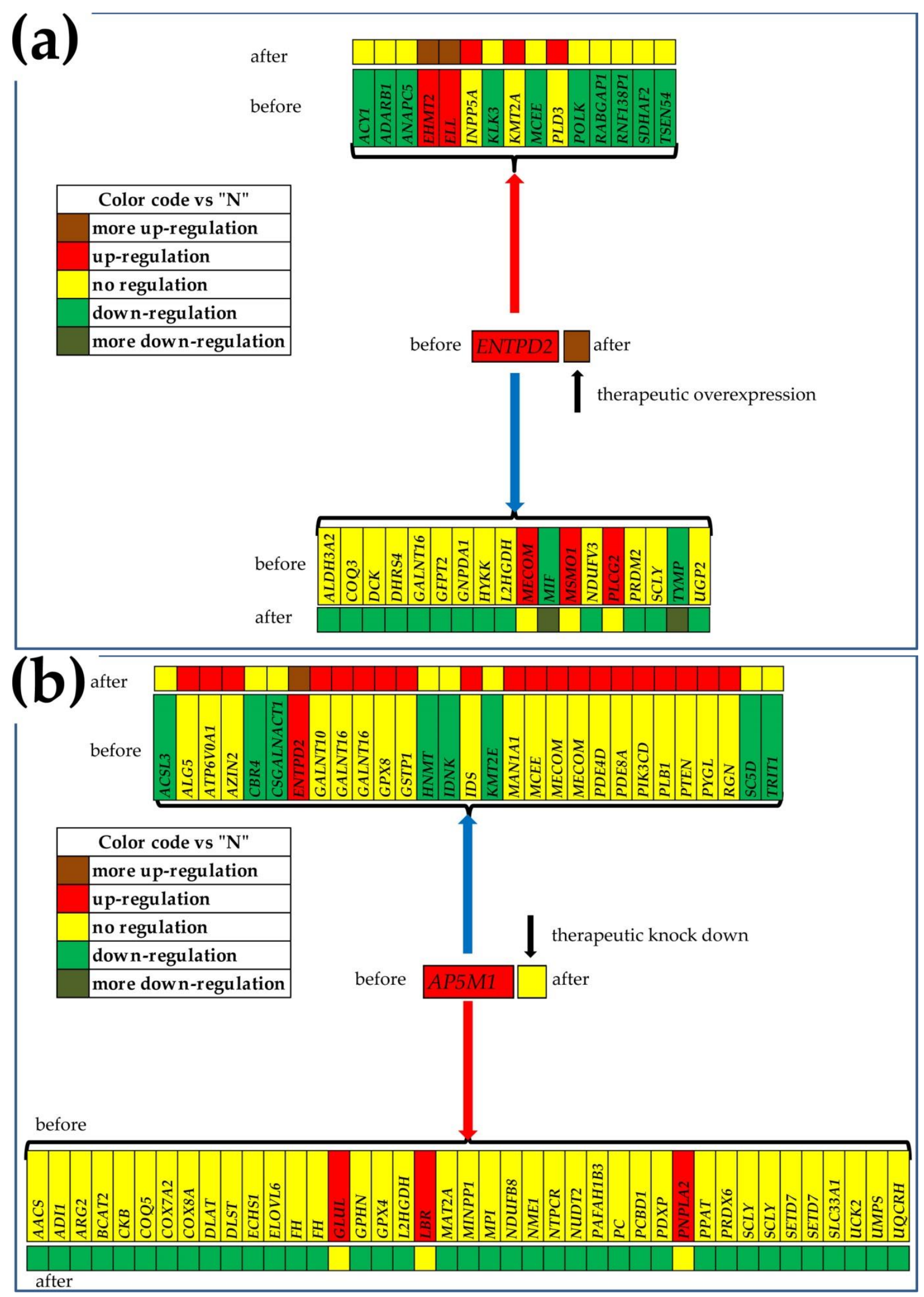




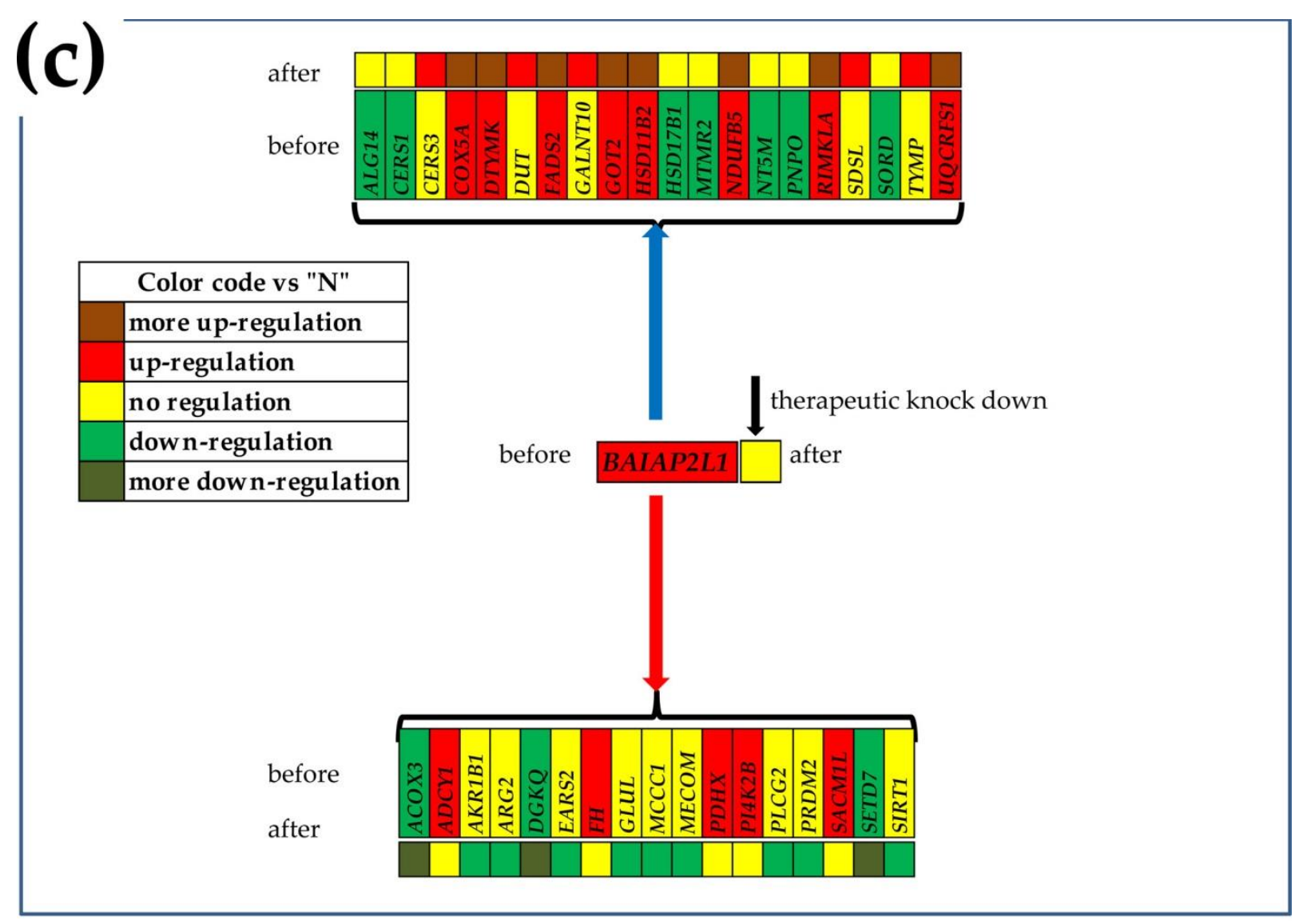

Figure 6 The significantly synergistically and antagonistically expressed metabolic genes with the corresponding GMR in the nodules: (a) " $\mathrm{A}$ ", (b) " $\mathrm{B}$ " and (c) " $\mathrm{C}$ " of the " $\mathrm{ABCN}$ " patient, and the predicted regulations after the therapeutic alteration of the GMR. The $\mathrm{red} / \mathrm{blue}$ arrow indicates the genes synergistically/antagonistically expressed with the GMR in that node. Gene symbol background indicates the status of that gene in the mentioned cancer nodule with respect to the surrounding normal tissue " $\mathrm{N}$ ".

\section{Discussion}

The purpose of this study was to provide justification and framework for the development of a personalized gene therapy approach of the prostate cancer management. As defined by the U.S. Food and Drug Administration (FDA) the gene therapy "seeks to modify or manipulate the expression of a gene or to alter the biological properties of living cells for therapeutic use" [55]. Development of effective PCa gene therapies was the objective of many research groups and numerous publications detail their findings (e.g. [56-61]. Some gene therapies (e.g. use of olaparib for HRR gene-mutated metastatic castration-resistant prostate cancer [62]) were already granted FDA approval (all FDA approved gene therapies for PCa listed in [63] and partially discussed in [64]). However, the endless diversity and the strong impact of certain individual characteristics on the PCa progression and treatment outcomes raise serious doubts about the value of such "good-for-everybody" gene therapies, refocusing the research on personalized solutions.

The report is based on transcriptomic data obtained in IacobasLab from 10 groups of samples: 3 distinct cancer nodules and the surrounding normal tissue from each of two PCa patients and two standard PCa cell lines. All experimental data were documented in the NCBI Gene Expression Omnibus. Because we tailor our approach of the prostate cancer genomics and gene therapy on the uniqueness of each affected man, and the data clearly show that even within the same tumor each cancer nodule has a distinct transcriptome, the sample size is not important. 
The power of the Genomic Fabric Paradigm [18] used here comes from extending the workable transcriptomic information by $4-5$ orders of magnitude by considering for each quantified gene all the ready available independent characteristics: AVE, REV and COR. While AVE (the average expression level across biological replicas) is used in all studies to determine whether the gene was significantly regulated in cancer with respect to the normal tissue, the ignored REV and COR bring additional fundamental information. Thus, REV (Relative Expression Variability) tells about cell's priorities in limiting the expression fluctuations of that gene, with genes critical for the cellular phenotypic expression constrained within very narrow intervals (low REV). On the other hand, COR (expression correlation) shows how much the expression fluctuations of one gene are correlated with the fluctuations of another gene, that is essential for the formation of gene networks. The independence and complementarity of these types of characteristics was proved in Figure 1. It was also proved in previous publications for apoptosis in human thyroid [21], chemokine signaling in human kidney [18] and mouse cortex [65], evading apoptosis in human prostate [31], ionic channels in mouse heart [66], and PI3K-AKT signaling in mouse hippocampus [67]).

Our research confirmed the numerous reports about the heterogeneity of PCa tumors at the gene expression profile level [10-17]. For this, we included Table 1 for the genes with the largest expression in each profiled region, and Table 3 and Figure 2 for the genes' contributions to the cancer transcriptomic departure from the normal tissue. Use of the Weighted Individual gene Regulation (WIR) and of the Weighted Pathway Regulation (WPR) provided more accurate measures of the transcriptomic alterations than the traditional percentages of up and down-regulated genes. Our results with distinct regulations even at the cancer nodule level within the same tumor (see Table 3 and Figure 2 in the present report, Figs. 2, 3 and 4 in [18] and [31]) question the idea of "transcriptomic signature", common for large cancer affected populations. We consider such cancer transcriptomic signatures as artefacts of the meta-analyses combining transcriptomic data from many individuals (not always demographically grouped as race, age and other major criterion), collected by numerous labs using (some)times distinct transcriptomic platforms and experimental protocols.

More importantly, we proved that the heterogeneity extends to the expression control (see Table 2 for the most stably and the most unstably expressed genes) and expression coordination (see Figure 3 for the networking of AKT2 and MTOR with their partners). These heterogeneities are even more important than that of the expression level because manipulation of the same gene may have different consequences in the distinct regions of the tumor. Thus, experimental over-expression or knock-down of one gene may trigger different responses of the homeostatic control mechanisms (higher in regions with low REV) and may differently remodel the gene networks.

The substantial heterogeneity of the gene expression level, control and networking other genes requires to go beyond the bulk tissue and profile each cancer clone in the tumor separately. This strategy (when served by adequate analytical tools) is a pre-requisite for designing personalized therapeutic strategies to selectively destroy the cancer clones with minimal impact on the surrounding healthy tissue.

We have introduced the GCH (Gene Commanding Height) score to determine how much influential a gene is in a particular region/condition and identified the GMR (gene master regulator) of each profiled phenotype as its top gene (highest GCH). The GMR enjoys the strongest protection of expression (lowest REV) while being coordinately expressed with many other genes.

Figure 4 shows that the GMR in one region has practically very little role in the other regions (much lower $\mathrm{GCH}$ ), which is of exceptionally important for designing a gene therapy that would selectively affects the phenotype ruled by the GMR.

In this report for metabolism (Figures 5 and 6 ) and in previous publications for basal transcription, RNA polymerase and cell-cycle [18], apoptosis [21], and enzymes [31], we included predictions of what might happen when targeting the GMR by a gene therapy. Unfortunately, there was no possibility to validate experimentally any of these predic- 
tions on the patients from which we have collected the prostate tissues. However, the GMR approach involving a monotonically ascendant relationship between the GCH score and the overall transcriptomic changes was validated by us on two human thyroid cancer cell lines stably transfected with four genes [20, 22]. Thus, transfection of the BCPAP (papillary) and 850C (anaplastic) thyroid cancer cells with DDX19B (DEAD-Box Helicase 19B), NEMP1 (nuclear envelope integral membrane protein 1), PANK2 (pantothenate kinase 2) and UBALD1 (UBA-like domain containing 1) induced significantly larger transcriptomic alterations in the cells where these genes had higher GCH.

\section{Conclusions}

For now, the approved FDA approved PCa gene therapies [63] target genes whose manipulation is considered as effective for all men, regardless of race, age, medical history, diet, habits and other risk factors whose dynamic combination makes each of them unique at each stage. In contrast, we propose to identify the most legitimate gene targets that will selectively destroy the cancer clones of the prostate of the current patient, now. Although a "good-for-everybody" drug seems much more advantageous from economical point of view, in time, our approach may become economically competitive. There are already numerous FDA-approved gene and therapy products [68] and, with the right stimulus, the industry will produce soon drugs based on CRISPR or other types of constructs to target almost all genes. When this will be the case, the oncologist would perform the transcriptomic analysis of tumor biopsies, identify the GMR of the cancer clones, ordered and administrate the right product to his patient. The treatment will have similar costs as the actual gene therapy but would be more efficient for the PCa person.

Author Contributions: Conceptualization, D.A.I.; methodology, S.I. and D.A.I..; software, D.A.I.; validation, S.I. and D.A.I.; formal analysis, D.A.I..; investigation, D.A.I.; resources, D.A.I.; data curation, D.A.I..; writing - original draft preparation, S.I.; writing-review and editing, D.A.I.; visualization, D.A.I.; supervision, D.A.I.; project administration, D.A.I.; funding acquisition, D.A.I. Both authors have read and agreed to the published version of the manuscript.

Funding: This research received no external funding.

Institutional Review Board Statement: The study was conducted according to the guidelines of the Declaration of Helsinki. At the time of the experiment (2016), the study was part of Dr. D.A. Iacobas' project approved by the Institutional Review Boards (IRB) of the New York Medical College's (NYMC) and Westchester Medical Center (WMC) Committees for Protection of Human Subjects. The approved IRB (L11,376 from 2 October 2015) granted access to frozen cancer specimens from the WMC Pathology Archives and depersonalized pathology reports, waiving the patient's informed consent.

Informed Consent Statement: Patient consent was waived due to the use of depersonalized pathology reports.

Data Availability Statement: Raw and processed gene expression data were deposited and are publicly accessible at: https://www.ncbi.nlm.nih.gov/geo/query/acc.cgi?acc=GSE72333, https://www.ncbi.nlm.nih.gov/geo/query/acc.cgi?acc=GSE72414, https://www.ncbi.nlm.nih.gov/geo/query/acc.cgi?acc=GSE133891, https://www.ncbi.nlm.nih.gov/geo/query/acc.cgi?\&acc=GSE133906, https://www.ncbi.nlm.nih.gov/geo/query/acc.cgi?acc=GSE168718, https://www.ncbi.nlm.nih.gov/geo/query/acc.cgi?acc=GSE183889.

Acknowledgments: This research was funded by the Texas A\&M University System Chancellor's Research Initiative (CRI) for the Center for Computational Systems Biology at Prairie View University.

Conflicts of Interest: The author declares no conflict of interest. 
1. Hatano, K.; Nonomura, N. Genomic Profiling of Prostate Cancer: An Updated Review. World J Mens Health. 2021. https://doi.org/10.5534/wjmh.210072. Epub ahead of print. PMID: 34448375.

2. Spratt, D.E. Prostate Cancer Transcriptomic Subtypes. Adv Exp Med Biol. 2019; 1210:111-120. doi: 10.1007/978-3-030-32656-2_6. PMID: 31900907.

3. Manceau, C.; Fromont, G.; Beauval, J.B.; Barret, E.; Brureau, L.; Créhange, G.; Dariane, C.; Fiard, G.; Gauthé, M.; Mathieu, R.; et al. On Behalf Of The Cc-Afu Cancerology Committee Of The Association Française d'Urologie. Biomarker in Active Surveillance for Prostate Cancer: A Systematic Review. Cancers (Basel). 2021; 13(17):4251. doi: 10.3390/cancers13174251. PMID: 34503059.

4. $\quad$ Evans, R.; Hawkins, N.; Dequen-O'Byrne, P.; McCrea, C.; Muston, D.; Gresty, C.; Ghate, S.R.; Fan, L.; Hettle, R.; Abrams K.R.; de Bono, J.; Hussain, M.; Agarwal, N. Exploring the Impact of Treatment Switching on Overall Survival from the PROfound Study in Homologous Recombination Repair (HRR)-Mutated Metastatic Castration-Resistant Prostate Cancer (mCRPC). Target Oncol. 2021. doi: 10.1007/s11523-021-00837-y. Epub ahead of print. PMID: 34478046.

5. Rogers, O.C.; Rosen, D.M.; Antony, L.; Harper, H.M.; Das, D.; Yang, X.; Minn, I.; Mease, R.C.; Pomper, M.G.; Denmeade, S.R. Targeted delivery of cytotoxic proteins to prostate cancer via conjugation to small molecule urea-based PSMA inhibitors. Sci Rep. 2021; 11(1):14925. doi: 10.1038/s41598-021-94534-5. PMID: 34290365; PMCID: PMC8295317.

6. Qureshi, Z.; Ahmad, M.; Yang, W.X.; Tan, F.Q. Kinesin 12 (KIF15) contributes to the development and tumorigenicity of prostate cancer. Biochem Biophys Res Commun. 2021; 576:7-14. doi: 10.1016/j.bbrc.2021.08.072..

7. Stachurska, A.; Elbanowski, J.; Kowalczyńska, H.M. Role of $\alpha 5 \beta 1$ and $\alpha v \beta 3$ integrins in relation to adhesion and spreading dynamics of prostate cancer cells interacting with fibronectin under in vitro conditions. Cell Biol Int. 2012; 36(10):883-92. doi: 10.1042/CBI20110522. PMID: 22686483.

8. Moghaddam, S.; Jalali, A.; O'Neill, A.; Murphy, L.; Gorman, L.; Reilly, A.M.; Heffernan, Á.; Lynch, T.; Power, R.; O'Malley, K.J. et al. Integrating Serum Biomarkers into Prediction Models for Biochemical Recurrence Following Radical Prostatectomy. Cancers (Basel). 2021; 13(16):4162. doi: 10.3390/cancers13164162. PMID: 34439316; PMCID: PMC8391749.

9. Jillson, L.K.; Rider, L.C.; Rodrigues, L.U.; Romero, L.; Karimpour-Fard, A.; Nieto, C.; Gillette, C.; Torkko, K.; Danis, E.; Smith, E.E. et al. MAP3K7 Loss Drives Enhanced Androgen Signaling and Independently Confers Risk of Recurrence in Prostate Cancer with Joint Loss of CHD1. Mol Cancer Res. 2021; 19(7):1123-1136. doi: 10.1158/1541-7786.MCR-20-0913. PMID: 33846123; PMCID: PMC8254790.

10. Kulac, I.; Roudier, M.P.; Haffner, M.C. Molecular Pathology of Prostate Cancer. Surg Pathol Clin. 2021; 14(3):387-401. doi: 10.1016/j.path.2021.05.004. PMID: 34373091.

11. Tolkach, Y.; Kristiansen, G. The Heterogeneity of Prostate Cancer: A Practical Approach. Pathobiology 2018, 85, 108-116, doi:10.1159/000477852.

12. Tu, S.M.; Zhang, M.; Wood, C.G.; Pisters, L.L. Stem Cell Theory of Cancer: Origin of Tumor Heterogeneity and Plasticity. Cancers (Basel). 2021; 13(16):4006. doi: 10.3390/cancers13164006. PMID: 34439162; PMCID: PMC8394880.

13. Berglund, E.; Maaskola, J.; Schultz, N.; Friedrich, S.; Marklund, M.; Bergenstråhle, J.; Tarish, F.; Tanoglidi, A.; Vickovic, S.; Larsson, L. et al. Spatial maps of prostate cancer transcriptomes reveal an unexplored landscape of heterogeneity. Nat. Commun. 2018, 9, 2419, doi:10.1038/s41467-018-04724-5.

14. Brady, L.; Kriner, M.; Coleman, I.; Morrissey, C.; Roudier, M.; True, L.D.; Gulati, R.; Plymate, S.R.; Zhou, Z.; Birditt, B. et al. Inter- and intra-tumor heterogeneity of metastatic prostate cancer determined by digital spatial gene expression profiling. Nat. Commun. 2021, 12, 1426, doi:10.1038/s41467-021-21615-4.

15. Melo, C.M.; Vidotto, T.; Chaves, L.P.; Lautert-Dutra, W.; Reis, R.B.D, Squire JA. The Role of Somatic Mutations on the Immune Response of the Tumor Microenvironment in Prostate Cancer. Int J Mol Sci. 2021; 22(17):9550. doi: 10.3390/ijms22179550. PMID: 34502458.

16. Makino, T.; Izumi, K.; Iwamoto, H.; Mizokami, A. Treatment Strategies for High-Risk Localized and Locally Advanced and Oligometastatic Prostate Cancer. Cancers 2021, 13, 4470. https://doi.org/10.3390/cancers13174470

17. Burgess, L.; Roy, S.; Morgan, S.; Malone, S. A Review on the Current Treatment Paradigm in High-Risk Prostate Cancer. Cancers 2021, 13, 4257. https://doi.org/10.3390/cancers13174257

18. Iacobas, D.A.; Mgbemena, V.E.; Iacobas, S.; Menezes, K.M.; Wang, H.; Saganti, P.B. Genomic Fabric Remodeling in Metastatic Clear Cell Renal Cell Carcinoma (ccRCC): A New Paradigm and Proposal for a Personalized Gene Therapy Approach. Cancers 2020, 12, 3678, doi:10.3390/cancers12123678.

19. Mateo J, McKay R, Abida W, Aggarwal R, Alumkal J, Alva A, Feng F, Gao X, Graff J, Hussain M, Karzai F, Montgomery B, Oh W, Patel V, Rathkopf D, Rettig M, Schultz N, Smith M, Solit D, Sternberg C, Van Allen E, VanderWeele D, Vinson J, Soule HR, Chinnaiyan A, Small E, Simons JW, Dahut W, Miyahira AK, Beltran H. Accelerating precision medicine in metastatic prostate cancer. Nat Cancer. 2020; 1(11):1041-1053. doi: 10.1038/s43018-020-00141-0. PMID: 34258585; PMCID: PMC8274325.

20. Iacobas, D.A.; Tuli, N.; Iacobas, S.; Rasamny, J.K.; Moscatello, A.; Geliebter, J.; Tiwari, R.M. Gene master regulators of papillary and anaplastic thyroid cancer phenotypes. Oncotarget 2018, 9, 2410-2424, doi:10.18632/oncotarget.23417.

21. Iacobas, D.A. Biomarkers, Master Regulators and Genomic Fabric Remodeling in a Case of Papillary Thyroid Carcinoma. Genes 2020, 11, 1030, doi:10.3390/genes11091030.

22. Iacobas, S.; Ede, N.; Iacobas, D.A. The Gene Master Regulators (GMR) Approach Provides Legitimate Targets for Personalized, Time-Sensitive Cancer Gene Therapy. Genes 2019, 10, 560, doi:10.3390/genes10080560.

23. Iacobas, D.A. The Genomic Fabric Perspective on the Transcriptome between Universal Quantifiers and Personalized Genomic Medicine. Biol. Theory 2016, 11, 123-137, doi:10.1007/s13752-016-0245-3. 
24. Iacobas, D.A. Powerful quantifiers for cancer transcriptomics. World J. Clin. Oncol. 2020, 11, 679-704, doi:10.5306/wjco.v11.i9.679.

25. Iacobas, D.A.; Iacobas, S.; Lee, P.R.; Cohen, J.E.; Fields, R.D. Coordinated Activity of Transcriptional Networks Responding to the Pattern of Action Potential Firing in Neurons. Genes 2019, 10, 754, doi:10.3390/genes10100754.

26. Petrucci, R.H.; Harwood, W.S.; Herring, F.G. General chemistry: principles and modern applications (8th ed.). Upper Saddle River, N.J: Prentice Hall. 2002; p. 37. ISBN 978-0-13-014329-7. LCCN 2001032331. OCLC 46872308.

27. Horoszewicz, J.S.; Leong, S.S.; Kawinski, E.; Karr, J.P.; Rosenthal, H.; Chu, T.M.; Mirand, E.A.; Murphy, G.P. LNCaP model of human prostatic carcinoma. Cancer Res. 198343 (4): 1809-18. PMID 6831420

28. Alimirah, F.; Chen, J.; Basrawala, Z.; Xin, H.; Choubey, D. DU-145 and PC-3 human prostate cancer cell lines express androgen receptor: implications for the androgen receptor functions and regulation. FEBS Lett. 2006580 (9): $2294-300$. doi:10.1016/j.febslet.2006.03.041

29. Remodeling of DNA transcription genomic fabric in Capridine-treated LNCaP human prostate cancer cell line. Available on line: https://www.ncbi.nlm.nih.gov/geo/query/acc.cgi?acc=GSE72414. Accessed 09/01/2021.

30. Remodeling of major genomic fabrics and their interplay in Capridine-treated DU145 classic human prostate cancer. Available on line at: https://www.ncbi.nlm.nih.gov/geo/query/acc.cgi?acc=GSE72333. Accessed 09/01/2021.

31. Iacobas, S.; Iacobas, D.A. A Personalized Genomics Approach of the Prostate Cancer. Cells 2021, 10 , 1644. https://doi.org/10.3390/cells10071644

32. Gene Commanding Height $(\mathrm{GCH})$ hierarchy in the cancer nucleus and cancer-free resection margins from a surgically removed prostatic adenocarcinoma of a $65 \mathrm{y}$ old black man. Available on line at: https://www.ncbi.nlm.nih.gov/geo/query/acc.cgi?\&acc=GSE133906. Accessed 09/01/2021

33. Genomic Fabric Remodeling in Prostate Cancer. Available on line at: https://www.ncbi.nlm.nih.gov/geo/query/acc.cgi?acc=GSE168718. Accessed 09/01/2021.

34. Gene Commanding Height $(\mathrm{GCH})$ hierarchy in the cancer nucleus and cancer-free resection margins from a surgically removed prostatic adenocarcinoma of a $47 \mathrm{y}$ old white man. Available on line at: https://www.ncbi.nlm.nih.gov/geo/query/acc.cgi?acc=GSE13389. Accessed 09/01/2021.1

35. Transcriptomic heterogeneity of the prostate cancer. Available on line at: https://www.ncbi.nlm.nih.gov/geo/query/acc.cgi?acc=GSE183889. Accessed: 09/12/2021

36. Agilent-026652 Whole Human Genome Microarray 4x44K v2. Available online: https://www.ncbi.nlm.nih.gov/geo/query/acc.cgi?acc=GPL13497 (accessed on 09/01/2021).

37. Stranger, B.E.; Forrest, M.S.; Clark, A.G.; Minichiello, M.J.; Deutsch, S.; Lyle, R.; Hunt, S.; Kahl, B.; Antonarakis, S.E.; Tavaré, S. et al. Genome-Wide Associations of Gene Expression Variation in Humans. PLOS Genetics 2005; 1(6): e78. https://doi.org/10.1371/journal.pgen.0010078

38. Guan, J.; Han, S.; Wu, J.; Zhang, Y.; Bai, M.; Abdullah, S.W.; Sun, S.; Guo, H. Ribosomal Protein L13 Participates in Innate Immune Response Induced by Foot-and-Mouth Disease Virus. Front Immunol. 2021; 12:616402. doi: 10.3389/fimmu.2021.616402.

39. Xu, H.; Liu, P.; Yan, Y.; Fang, K.; Liang, D.; Hou, X.; Zhang, X.; Wu, S.; Ma, J.; Wang, R. et al. FKBP9 promotes the malignant behavior of glioblastoma cells and confers resistance to endoplasmic reticulum stress inducers. J Exp Clin Cancer Res. 2020; 39(1):44. doi: 10.1186/s13046-020-1541-0.

40. Jiang, F.N.; Dai, L.J.; Yang, S.B.; Wu, Y.D.; Liang, Y.X.; Yin, X.L.; Zou, C.Y.; Zhong, W.D. Increasing of FKBP9 can predict poor prognosis in patients with prostate cancer. Pathol Res Pract. 2020; 216(1):152732. doi: 10.1016/j.prp.2019.152732.

41. Macauda, A.; Piredda, C.; Clay-Gilmour, A.I.; Sainz, J.; Buda, G.; Markiewicz, M.; Barington, T.; Ziv, E.; Hildebrandt, M.A.T.; Belachew, A.A. et al. Expression quantitative trait loci of genes predicting outcome are associated with survival of multiple myeloma patients. Int J Cancer. 2021; 149(2):327-336. doi: 10.1002/ijc.33547.

42. Wang, J.; Luo, Q.; Liu, M.; Zhang, C.; Jia, Y.; Tong, R.; Yang, L.; Fu, X. TBRG4 silencing promotes progression of squamous cell carcinoma via regulation of CAV-1 expression and ROS formation. Cell Mol Biol (Noisy-le-grand). 2020; 66(2):157-164. PMID: 32415943.

43. Huang, F.; Zhou, P.; Wang, Z.; Zhang, X.L.; Liao, F.X.; Hu, Y.; Chang, J. Knockdown of TBRG4 suppresses proliferation, invasion and promotes apoptosis of osteosarcoma cells by downregulating TGF- $\beta 1$ expression and PI3K/AKT signaling pathway. Arch Biochem Biophys. 2020; 686:108351. doi: 10.1016/j.abb.2020.108351.

44. Varghese, R.T.; Liang, Y.; Guan, T.; Franck, C.T.; Kelly, D.F.; Sheng, Z. Survival kinase genes present prognostic significance in glioblastoma. Oncotarget. 2016; 7(15):20140-51. doi: 10.18632/oncotarget.7917.

45. Bashanfer, S.A.A.; Saleem, M.; Heidenreich, O.; Moses, E.J.; Yusoff, N.M. Disruption of MAPK1 expression in the ERK signalling pathway and the RUNX1-RUNX1T1 fusion gene attenuate the differentiation and proliferation and induces the growth arrest in $\mathrm{t}(8 ; 21)$ leukaemia cells. Oncol Rep. 2019; 41(3):2027-2040. doi: 10.3892/or.2018.6926.

46. Wang, A.; Zhao, C.; Liu, X.; Su, W.; Duan, G, Xie, Z.; Chu, S.; Gao, Y. Knockdown of TBRG4 affects tumorigenesis in human H1299 lung cancer cells by regulating DDIT3, CAV1 and RRM2. Oncol Lett. 2018; 15(1):121-128. doi: 10.3892/ol.2017.7328.

47. Rao, Y.; Liu, H.; Yan, X.; Wang, J. In Silico Analysis Identifies Differently Expressed lncRNAs as Novel Biomarkers for the Prognosis of Thyroid Cancer. Comput Math Methods Med. 2020; 2020:3651051. doi: 10.1155/2020/3651051.

48. Danielpour, D.; Purighalla, S.; Wang, E.; Zmina, P.M.; Sarkar, A.; Zhou, G. JAB1/COPS5 is a putative oncogene that controls critical oncoproteins deregulated in prostate cancer. Biochem Biophys Res Commun. 2019; 518(2):374-380. doi: 10.1016/j.bbrc.2019.08.066. 
49. mTOR signaling pathway. Available on line at https://www.genome.jp/pathway/hsa04150. Accessed 09/01/2021.

50. Hua H., Kong Q., Zhang H., Wang J., Luo T., Jiang Y. Targeting mTOR for cancer therapy. J. Hematol. Oncol. $2019 ; 12: 71$. doi: 10.1186/s13045-019-0754-1.

51. Gong, C.; Qu, S.; Lv, X.B.; Liu, B.; Tan, W.; Nie, Y.; Su, F.; Liu, Q.; Yao, H.; Song, E. BRMS1L suppresses breast cancer metastasis by inducing epigenetic silence of FZD10. Nat Commun. 2014; 5:5406. doi: 10.1038/ncomms6406.

52. Wendel, H.G.; Silva, R.L.; Malina, A.; Mills, J.R.; Zhu, H.; Ueda, T.; Watanabe-Fukunaga, R.; Fukunaga, R.; Teruya-Feldstein, J.; Pelletier, J. et al. Dissecting eIF4E action in tumorigenesis. Genes Dev. 2007; 21(24):3232-7. doi: 10.1101/gad.1604407.

53. Prostate cancer pathway. Available on line at: https://www.genome.jp/pathway/hsa05215. Accessed 09/01/2021.

54. KEGG pathway database. Available on line: https://www.genome.jp/kegg/pathway.html. Accessed 09/01/2021.

55. What is gene Available on line: https://www.fda.gov/vaccines-blood-biologics/cellular-gene-therapy-products/what-gene-therapy. Accessed 09/20/2021.

56. Harrington, K.J.; Spitzweg, C.; Bateman, A.R.; Morris, J.C.; Vile, R.G. Gene therapy for prostate cancer: current status and future prospects. J Urol. 2001; 166(4):1220-33. doi: 10.1016/s0022-5347(05)65742-4.

57. Ikegami, S.; Tadakuma, T.; Ono, T.; Suzuki, S.; Yoshimura, I.; Asano, T.; Hayakawa, M. Treatment efficiency of a suicide gene therapy using prostate-specific membrane antigen promoter/enhancer in a castrated mouse model of prostate cancer. Cancer Sci. 2004; 95(4):367-70. doi: 10.1111/j.1349-7006.2004.tb03217.x.

58. Satoh, T.; Irie, A.; Egawa, S.; Baba, S. In situ gene therapy for prostate cancer. Curr Gene Ther. 2005; 5(1):111-9. doi: 10.2174/1566523052997523.

59. Cai, Z.; Lv, H.; Cao, W.; Zhou, C.; Liu, Q.; Li, H.; Zhou, F. Targeting strategies of adenovirus-mediated gene therapy and virotherapy for prostate cancer (Review). Mol Med Rep. 2017; 16(5):6443-6458. doi: 10.3892/mmr.2017.7487.

60. de Bono, J.; Mateo, J.; Fizazi, K.; Saad, F.; Shore, N.; Sandhu, S.; Chi, K.N.; Sartor, O.; Agarwal, N.; Olmos, D.; et al. Olaparib for Metastatic Castration-Resistant Prostate Cancer. N. Engl. J. Med. 2020, 382, 2091-2102.

61. Talkar, S.S.; Patravale, V.B. Gene Therapy for Prostate Cancer: A Review. Endocrine, Metabolic E Immune Disorders - Drug Targets 2021; 21(3). https://doi.org/10.2174/1871530320666200531141455

62. U.S. Food and Drug Administration, FDA. Fda Approves Olaparib for Hrr Gene-Mutated Metastatic Castration-Resistant Prostate Cancer. Available online: https://www.fda.gov/drugs/resources-information-approved-drugs/fda-approves-olaparib-hrr-gene-mutated-metastaticcastration-resistant-prostate-cancer. Accessed on 09/01/2021.

63. U.S. Food and Drug Administration, FDA, approved treatments for prostate cancer. Available on line: https://search.usa.gov/search?utf8=\%E2\%9C\%93\&affiliate=fda\&sort by=\&query=prostate+cancer\&commit=Search. $\quad$ Accessed 09/20/2021.

64. Zhang, J.; Sun, J.; Bakht, S.; Hassan, W. Recent Development and Future Prospects of Molecular Targeted Therapy in Prostate Cancer. Curr Mol Pharmacol. 2021. doi: 10.2174/1874467214666210608141102.

65. Iacobas, D.; Wen, J.; Iacobas, S.; Schwartz, N.; Putterman, C. Remodeling of Neurotransmission, Chemokine, and PI3K-AKT Signaling Genomic Fabrics in Neuropsychiatric Systemic Lupus Erythematosus. Genes 2021, $12,251$. https://doi.org/10.3390/genes12020251

66. Iacobas, S.; Amuzescu, B.; Iacobas, D.A. Transcriptomic uniqueness and commonality of the ion channels and transporters in the four heart chambers, Sci Rep. 2021, 11(1):2743. doi: 10.1038/s41598-021-82383-1.

67. Iacobas, D.A.; Wen, J.; Iacobas, S.; Putterman, C.; Schwartz, N. TWEAKing the Hippocampus: The Effects of TWEAK on the Genomic Fabric of the Hippocampus in a Neuropsychiatric Lupus Mouse Model. Genes 2021, 12, 1172. https://doi.org/10.3390/genes12081172

68. U.S. Food and Drug Administration approved cellular and gene therapy products. Available on line: https://www.fda.gov/vaccines-blood-biologics/cellular-gene-therapy-products/approved-cellular-and-gene-therapy-prod ucts. Accessed 09/20/2021. 